\title{
BALANCING ONLINE AND FACE-TO-FACE TEACHING AND LEARNING ACTIVITIES
}

\author{
Emiel van Puffelen \\ 4TU.Centre for Engineering Education, \\ Wageningen University \& Research, The Netherlands \\ Melanie van Berkum, Julia Diederen \\ Department of Agrotechnology and Food Sciences, \\ Wageningen University \& Research, The Netherlands
}

\begin{abstract}
The core of university course design is the selection and combination of Teaching and Learning Activities (TLAs). TLAs may involve various types of interaction, either face-to-face or with and through media. Traditional media such as books are increasingly being supplemented with many types of online media such as short video presentations known as knowledge clips. Wageningen University introduced knowledge clips to several second-year Food Technology courses, partially shifting from face-to-face interactions to online activities that facilitate acquiring, inquiring and practicing. Student questionnaires and a student group interview were used to reveal differences in student preferences towards knowledge clips and the other TLAs. Knowledge clips seem to be valuable parts of courses and work well in general, although students prefer to combine them with some face-to-face interaction. Besides individual preference, there seem to be two main reasons for this: (1) watching a large number of clips requires a considerable amount of discipline and a face-to-face meeting during the course is an intermediate goal to work towards, and (2) when knowledge clips are more difficult and raise questions, students prefer to work in a room with access to a teacher.
\end{abstract}

\section{KEYWORDS}

Teaching and Learning Activities, Face-to-face, Online, Course design, Knowledge Clips, CDIO standards: $5,6,7,8,10,11$

\section{INTRODUCTION}

Developing university courses usually involves a cycle of designing, building, executing and evaluating. The design phase should be based on a well-constructed curriculum and properly formulated Intended Learning Outcomes. The core of course design consists of the selection and combination of Teaching and Learning Activities (TLAs). Generally, a smart design involving a combination of different types of TLAs is required to create a top-quality university course (van Puffelen, 2017). One option is to develop a course with information-gathering activities for students, devoting class time to discussions, peer interactions, and the assimilation of knowledge (Mazur, 2009). This flipping of the classroom approach requires the provision of media to support students in their information gathering. 
The use of traditional media such as books is increasingly being supplemented with several types of online media. These media can be used to restrict face-to-face interactions to situations in which they are really needed, such as activities to follow up on learning achieved using media or activities aimed at higher-level learning outcomes. The result is that online learning becomes a larger part of student learning activities; however, this might not always be without consequences for learning motivation. Christiansen et al. (2017) found that students achieved lower scores on quizzes performed at home compared with in class. Survey feedback showed a strong preference for taking quizzes in class and indications that take-home quizzes demotivated attendance and the pre-class watching of videos. Pfeiffer, Scheiter, and Gemballa (2012) found that students who had prepared for a task using digital videos were less motivated than students who were trained in class, although a combination of both approaches was best.

Massive Open Online Courses (MOOCs) can even be restricted to $100 \%$ online TLAs.

A literature review (Hew \& Cheung, 2014) showed that many MOOCs have a structure equivalent to university courses, using video lectures, examinations and/or individual final projects, as well as online discussions. The main differences found between MOOCs and university courses were that MOOCs had larger and more diverse student enrolment, higher drop-out rates and a relative lack of instructor presence or support. MOOCs also suffer from a lack of student response in the online discussion and, for the teachers, the sense of speaking into a vacuum because of the absence of student immediate feedback. These findings could indicate that learning is less effective with MOOCs due to a lack of face-to-face interaction.

The low completion rates of MOOCs (Hew \& Cheung, 2014; Jordan, 2015) might also be partially explained by the selection and intentions of MOOC students. Since most users of MOOCs are not part of a study programme, completing the whole MOOC is not necessary. Still, it is wise to investigate student perception when increasing the use of online activities in university courses, as well as the possible limitations. The student perception might be influenced by the way that online and face-to-face activities are mixed. Figure 1 (based on Laurillard $(2012,2016)$ ) gives an overview of types of learning; acquiring, inquiring, producing, practicing, discussing and collaborating. Courses can contain these types of learning using any combination of online and face-to-face TLAs.

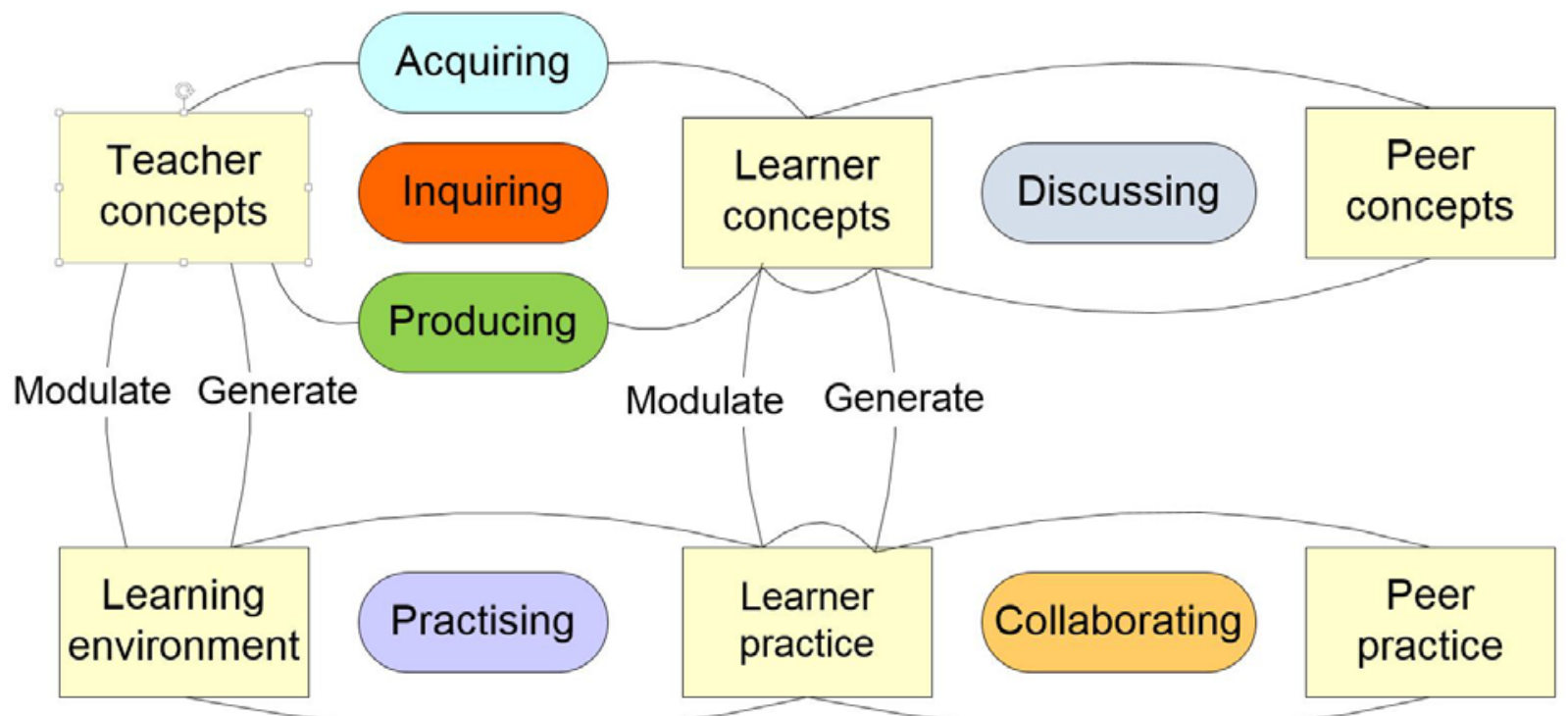

Figure 1. Types of learning targeted by TLAs (based on Laurillard, 2012, 2016) 
Acquiring knowledge can be supported online using knowledge clips (short video presentations of a single topic). Long, Logan, and Waugh (2016) found that, for pre-class learning, videos should be combined with other activities to ensure students have learned the knowledge covered in the videos and are prepared for the in-class activities. Fabregat-Sanjuan et al. (2017) successfully used out of class self-assessment in combination with online video clips to achieve this, while Moos and Bonde (2016) found that embedding prompts in the video had a positive effect, causing students to better self-regulate their learning.

Wageningen University has introduced knowledge clips and other online TLAs, such as digital exercises and assignments with built-in feedback, in several second-year food technology courses. The implementation of online TLAs has led to a partial shift from face-to-face to online activities for acquiring, inquiring and practicing activities. The implementation of knowledge clips and other online TLAs in combination with face-to-face TLAs has been evaluated at the course level. This paper focuses on the student perceptions of the resulting TLA combinations used in two second-year bachelor's courses with different TLA combinations: Food Microbiology and Mathematical Concepts for Food Technology.

\section{METHODS}

Course guides and evaluations of the courses Food Microbiology (Course 1) and Mathematical Concepts for Food Technology (Course 2) were studied to create an overview of their TLAs. The overview was used to design questionnaires, which were also discussed in detail with the course co-ordinators.

The paper-based questionnaires were provided to the students immediately after the completion of their respective course exams. In these questionnaires, students were asked to indicate the extent to which they agreed or disagreed with statements about the TLAs using a five-point Likert scale, ranging from 'strongly disagree' (1) to 'strongly agree' (5). Students were also asked about their attendance and the percentage of exercises completed using a fivecategory scale: 0-20\% (1), 20-40\% (2), 40-60\% (3), 60-80\% (4) and 80-100\% (5) attendance. Students were asked to participate in a semi-structured group interview one month after the course, during which the questionnaire was discussed in detail.

Course 1 starts with a few introductory lectures and has $\sim 60$ knowledge clips (each not more than 10 minutes in length) that replace lectures and offer corresponding digital exercises. Several contact points are scheduled throughout the course, in which students can ask questions. During tutorials, students work on digital assignments with built-in feedback. The tutorials are held in computer rooms, with teachers available to answer questions. Live question hours are scheduled after the tutorials, where the teacher discusses questions about the tutorial that are posted on a digital blog. The pre-lab activities are digital activities held in a scheduled computer room, with teacher available to answer questions and attendance being compulsory. For the pre-lab and lab classes, students are offered about 30 knowledge clips to explain several techniques.

In Course 2, students work on $\sim 30$ exercises, each consisting of 10 to 20 calculation questions. Every day, computer rooms are scheduled for the students and several teachers are available to provide help; however, attendance is not compulsory. In addition to the exercises, students work on three digital cases, which are large digital assignments consisting of several interactive questions with built-in feedback, which student need to finish within a scheduled time slot. The course has no lectures but contains several types of 
knowledge clip: theory clips (introducing a theory in general), introductory clips (introducing the exercise) and wrap-up clips (explaining the answers).

Course 1 was taken by 288 students and Course 2 was taken by 197 students. Both courses were scheduled during the same term, and most students $(-160)$ took both courses simultaneously.

\section{RESULTS}

\section{Questionnaires}

The questionnaire results for Course 1 are shown in Table 1, with the scores (out of 5) for how valuable students regarded each type of TLA shown in bold. Both the lowest and highest scores were for an in-person TLA; introductory lectures: 2.97 and laboratory classes: 4.21.

The general score for the TLAs was above the neutral score of 3.0, and the differences between them are small (insignificant) compared with their standard deviations (ranging from 0.68 to 1.30$)$.

Table 1. Questionnaire results for Course 1, out of a maximum score of $5 . n=101-122$.

\begin{tabular}{|l|r|r|}
\hline TLA questions & Mean & SD \\
\hline The introductory lectures were valuable. & 2.97 & 1.25 \\
There was inconvenient overlap between introductory lectures and knowledge clips. & 3.40 & 1.05 \\
What percentage of the introductory lectures did you attend? & 3.87 & 1.33 \\
& 3.24 & 1.00 \\
I am satisfied with the help of the teachers/supervisors during the tutorials. & 2.40 & 1.53 \\
What percentage of the tutorials did you attend? & 4.14 & 0.95 \\
The knowledge clips were a valuable part of the course. & 4.54 & 0.94 \\
What percentage of the knowledge clips did you watch? & 3.81 & 0.83 \\
The exercises (corresponding to the knowledge clips) were valuable. & 4.23 & 1.07 \\
What percentage of the exercises did you make? & & \\
& 3.79 & 0.90 \\
The digital assignments were a valuable part of the course. & 3.05 & 0.98 \\
& 3.16 & 1.07 \\
The pre-lab activities were a valuable part of the course. & 3.21 & 0.96 \\
The pre-lab activities were a good replacement for part of the laboratory classes. & 4.07 & 1.20 \\
The knowledge clips of the pre-lab activities were a valuable part of the course. & 2.97 & 1.00 \\
What percentage of these knowledge clips did you watch? & 4.00 & 1.33 \\
The exercises of the pre-lab activities were valuable. & & \\
What percentage of these exercises did you make? & 4.21 & 0.68 \\
& & \\
The laboratory classes were a valuable part of the course. & 3.22 & 1.02 \\
The life question hours were a valuable part of the course. (n = 65) & 1.83 & 1.35 \\
What percentage of the life question hours did you attend? & & \\
& 3.38 & 1.30 \\
I am satisfied that the knowledge clips replaced part of the lectures. & 3.37 & 1.35 \\
I prefer to have more lectures instead of knowledge clips. & 3.44 & 1.15 \\
I prefer to have more face-to-face contact with teachers/supervisors during course. & \\
& & \\
\hline Questions scale: 'strongly disagree' (1) to 'strongly agree' (5) & $80-100 \%$ \\
Attendance / completion scale: 1 = 0-20\%, 2 = 20-40\%, 3 = 40-60\%, 4 = 60-80\%, 5 &
\end{tabular}


The questions for Course 1 were answered by between 101 and 122 students, with the exception of the question on "life question hours", which was answered by just 65 students. This low response rate could be explained by the low attendance score (1.83) for life question hours, although the students that did answer this question appreciated this TLA as much as the others, giving it an above-neutral score (3.22). The attendance scores for the other TLAs were 3.87-4.23, indicating an average attendance of about 60-80\%. Again, the standard deviations showed a relatively large variation in the scores.

The tutorials and pre-lab activities both combined digital exercises and knowledge clips. The questions on each of these components had scores similar to those of the main TLAs (all above the neutral score, with small differences relative to the larger standard deviations).

The results for the final three questions could indicate that students do not object to knowledge clips in general, but that for this course the amount face-to-face contact was a bit too low.

The questionnaire results for Course 2 are shown in Table 2. The range of scores for the TLAs are comparable to those of the first course, 2.99-4.01, with most above the neutral score of 3.0. Again, the differences are small (insignificant) compared with the relatively large standard deviations, which range from 0.73 to 1.20 .

Table 2. Questionnaire results for Course 2, out of a maximum score of 5. $n=129-149$.

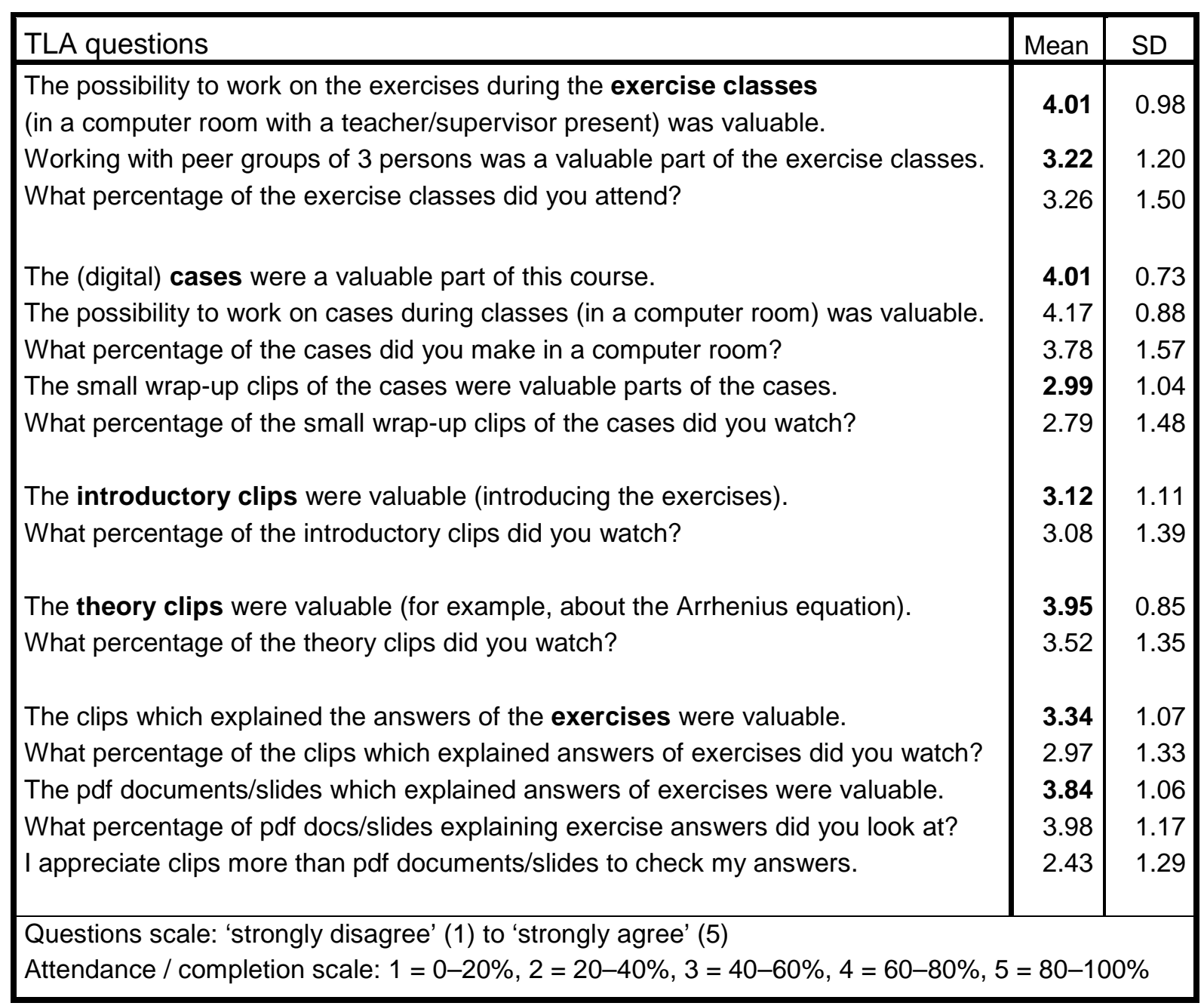


The questions for Course 2 were answered by between 129 and 149 students. There were four different types of clips in this course: introductory clips (to introduce exercises), theory clips (to explain theory), wrap-up clips (to wrap-up the case) and screen-recording clips (to explain the answers of the exercises). The mean watch rate for the clips was between 2.79 and 3.52 , both above and below the neutral score of $3(40-60 \%)$, and again, there were relatively large standard deviations.

\section{Semi-structured group interview}

Five students participated in the interview about the questionnaires, which yielded valuable remarks and explanations of the questionnaire answers for the courses, both individually and in combination.

\section{Knowledge clips}

Students indicated that the combination of Courses 1 and 2 was difficult. Both courses had many knowledge clips, which required a lot of discipline to complete. Students were used to the learning activities of courses from the previous year, which did not include the use of knowledge clips. Students stated that they needed more time to get familiar with the knowledge clips and explained: 'We had to watch about 60 knowledge clips. That is quite a lot'.

For Course 1, a schedule was provided for watching the clips and completing the corresponding exercises. The students appreciated the schedule but found it difficult to follow because it required a lot of discipline. Some students also missed having contact with fellow students and teachers, and therefore made use of available rooms to watch the clips together with other students. Other students appreciated the fact that they were able to watch the knowledge clips from home and were not obliged to visit the campus.

The students watched the knowledge clips but, although it was explained beforehand, did not always know where and how to ask questions about their content. They did not always understand how the knowledge clips related to information provided in the other (online) learning activities.

The appreciation for online TLAs depended on the nature of the course. For the explanation of concepts, knowledge clips were found to be sufficient without any further supervision. In Course 2, where students needed to make difficult calculations, they appreciated the possibility of watching knowledge clips and completing exercises in a room with teachers available. For this type of learning, students would appreciate some whole-class teaching; for example, the explanation of an exercise.

Students do not agree on whether lectures should be replaced with knowledge clips. Some students appreciated the flexibility of knowledge clips and were happy for their contact with teachers to be limited. Other students missed having contact with teachers and fellow students and were in favour of TLAs that take place at the university, with the supervision of teachers.

In general, the knowledge clips were considered a valuable part of the course, but students thought they should be combined with opportunities for teacher interaction. 


\section{Student preferences for Courses 1 and 2}

Small differences in the attendance rates and evaluations of usefulness of the TLAs between the two courses could be explained by their difficulty levels: students considered the knowledge clips and exercises of Course 1 easier because they largely comprised explanations of concepts. Students did not have many questions related to this and could complete everything online without supervision. The content of Course 2 was considered more difficult because the knowledge clips contained explanations of the calculation exercises and raised more questions; therefore, students preferred to work in a room with supervision. Also for this purpose, most students tended to prefer slides above knowledge clips containing an explanation of the calculation exercises, because this made it easier to follow the calculation. Some students indicated that they did not attend all the tutorials, and preferred to complete (some of) the exercises at home.

In Course 2, there was no whole-classroom teaching; the students were allowed to form groups and solve the exercises together, stimulating interaction. Students did not always find this useful because it took them longer to finish the exercises. Some would have appreciated more whole-classroom teaching, which keeps them more motivated and able to sustain the required pace; however, other students appreciated the fact that the TLAs were digital, enabling them to work from home at their own pace.

\section{DISCUSSION AND CONCLUSIONS}

\section{TLA combinations}

The questionnaires and interview show that the knowledge clips seem to work well in general. They also show that students prefer to combine knowledge clips with other TLAs. Besides preference, there seem to be two reasons for that: watching a large amount of clips requires a considerable amount of discipline and face-to-face meetings in between sets intermediate goals to work for. Also when knowledge clips are more difficult (e.g. explaining a calculation) and raise questions students prefer to work in a room with supervision.

The large standard deviations show that students differ in preference for all the online and face-to-face TLAs used in the courses. Boelens, De Wever, and Voet (2017) formulated four goals for the design of blended courses: (1) incorporating flexibility, (2) stimulating interaction, (3) facilitating students' learning processes and (4) fostering an affective learning climate.

It seems that the two courses reached at least the goals 1 and 3 to some extend as all TLAs were scored as neutral or above despite differences in student preferences towards the various TLA types. This might indicate that the different TLA types offered, enabled most students to find TLA combinations that worked for them.

\section{Implementation}

When online TLAs (such as knowledge clips) are introduced, it is important that students receive guidance on how to work with them to reach the learning goals. In that way, students can become familiar with the new TLAs, decide whether a learning activity is useful for them to attend, and understand how to make effective use of it. Study programmes should slowly introduce knowledge clips; a sudden change from courses with only lectures and group work to courses with knowledge clips and digital learning material might confuse students in their learning strategies. 


\section{FUTURE WORK}

Wageningen University continues to monitor ongoing interventions in the Food Technology courses, and the future comparison of more course types may yield new insights. One option would be to additionally survey whether a course stimulates interactions and foster an affective learning climate. This might be combined with courses containing online and face-to-face TLAs that facilitate discussion and collaboration (right side of figure 1).

\section{ACKNOWLEDGEMENTS}

We would like to thank Tessa Schoones for her work gathering data, Heidy den Besten and Karin Schroën for coordinating the courses while enabling our research, and Anja Janssen and Han Smolenaars for their advice on courses and questions.

\section{REFERENCES}

Boelens, R., De Wever, B., \& Voet, M. (2017). Four key challenges to the design of blended learning: A systematic literature review. Educational Research Review, 22, (Supplement C), 1-18. doi:https://doi.org/10.1016/j.edurev.2017.06.001

Christiansen, M. A., et al. (2017). In-Class Versus At-Home Quizzes: Which is Better? A Flipped Learning Study in a Two-Site Synchronously Broadcast Organic Chemistry Course. Journal of Chemical Education, 94, (2), 157-163. doi:10.1021/acs.jchemed.6b00370

Fabregat-Sanjuan, A., et al. (2017). Laboratory 3.0: Manufacturing Technologies Laboratory Virtualization with a Student-Centred Methodology. Journal of Technology and Science Education, 7, (2), 184-202.

Hew, K. F., \& Cheung, W. S. (2014). Students' and instructors' use of massive open online courses (MOOCs): Motivations and challenges. Educational Research Review, 12, (Supplement C), 45-58. doi:https://doi.org/10.1016/j.edurev.2014.05.001

Laurillard, D. (2012). Teaching as a design science: Building pedagogical patterns for learning and technology: Routledge Taylor \& Francis Group.

Laurillard, D. (2016). Learning in the context of education; The conversational Framework. Presentation on the Online Educa Berlin 2016, Berlin, Retrieved from http://ignatiawebs.blogspot.nl/2016/12/limitlesslearning-plenary-oeb16-on.html

Long, T., Logan, J., \& Waugh, M. (2016). Students' Perceptions of the Value of Using Videos as a Preclass Learning Experience in the Flipped Classroom. TechTrends, 60, (3), 245-252. doi:10.1007/s11528-016-0045-4

Mazur, E. (2009). Farewell, Lecture? Science, 323, (5910), 50-51. doi:10.1126/science.1168927

Moos, D. C., \& Bonde, C. (2016). Flipping the Classroom: Embedding Self-Regulated Learning Prompts in Videos. Technology, Knowledge and Learning, 21, (2), 225-242. doi:10.1007/s10758-015-9269-1

Pfeiffer, V. D. I., Scheiter, K., \& Gemballa, S. (2012). Comparing and Combining Traditional Teaching Approaches and the Use of Video Clips for Learning How to Identify Species in an Aquarium. Journal of Biological Education, 46, (3), 140-148.

van Puffelen, E. A. M. (2017). Designing blended engineering courses. Proceedings of the 45th SEFI Annual Conference 2017, Angra do Heroísmo - Terceira, Azores, Portugal. 1308-1312. http://edepot.wur.nl/424719 


\section{BIOGRAPHICAL INFORMATION}

Ir. Emiel A.M. van Puffelen is the leader of the 4TU.Centre for Engineering Education at Wageningen University \& Research. At Wageningen University he has supervised the creation and full scale operation of the University Teaching Qualification programme. He also developed MOOC production teams, knowledge clip studios, the education innovation consultancy, the educational portal and the team for the innovation of the IT learning environment. He was previously a senior consultant in the innovation of higher education, working for national organisations, and has a special interest in activating learning, blended learning, training teaching staff and the novel design of curricula and courses.

Melanie van Berkum MSc is an educational developer and teacher in the Food Process Engineering group at Wageningen University \& Research. She has a Master's degree in Science Education and Communication.

dr.ir. Julia Diederen is a lecturer in the Department of Agrotechnology and Food Sciences at Wageningen University \& Research. She has a $\mathrm{PhD}$ in designing digital learning materials for food chemistry education, and is currently designing virtual laboratory simulations to foster the acquisition of scientific skills. She is also involved in several education innovation projects.

\section{Corresponding author}

Ir. Emiel A.M. van Puffelen

Wageningen University \& Research P.O. Box 9101, 6700 HB Wageningen

The Netherlands

31-317-484568

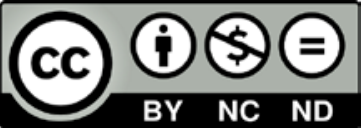

This work is licensed under a Creative Commons Attribution-NonCommercialNoDerivs 4.0 International License.

emiel.vanpuffelen@wur.nl 